\title{
Construction, expression and binding specificity of bispecific CD3 $\times$ VEGFR-2 and CD3 $\times$ NCAM antibodies in the single chain and diabody format
}

\author{
Anke Kopacek ${ }^{1}$, Thomas Böldicke ${ }^{1}$, Sarah Lergenmüller ${ }^{1}$, Frank Berthold ${ }^{2}$, Markus Jensen², \\ Peter P. Müller ${ }^{1}$, Ludger Grosse-Hovest ${ }^{3}$ \\ ${ }^{1}$ Helmholtz Center for Infection Research, Department of Molecular Biotechnology, Braunschweig, Germany \\ ${ }^{2}$ Department of Pediatric Oncology and Hematology, University of Cologne, University Hospital Cologne, Cologne, Germany \\ ${ }^{3}$ Institute for Cell Biology, Department of Immunology, Eberhard Karls University, Tübingen, Germany \\ Email: anke.kopacek@googlemail.com, thomas.boeldicke@helmholtz-hzi.de, sarah.lergenmueller@gmx.de, \\ frank.berthold@uk-koeln.de, jensen@uni-koeln.de, pmu@helmholtz-hzi.de, ludger.grosse-hovest@uni-tuebingen.de
}

Received 8 March 2013; revised 19 April 2013; accepted 13 May 2013

Copyright (c) 2013 Anke Kopacek et al. This is an open access article distributed under the Creative Commons Attribution License, which permits unrestricted use, distribution, and reproduction in any medium, provided the original work is properly cited.

\begin{abstract}
Bispecific antibodies are recombinant proteins with novel immunological properties and therapeutic potential. Recombinant protein quality and activity of several bispecific antibodies comprising different variable domain combinations with respect to the parental monospecific single chain fragments (scFv) were evaluated after expression in bacteria or mammalian cells. The parental scFv proteins humanized antiNCAM scFv, murine anti-VEGFR-2 scFv, murine and humanized anti-CD3 scFv, respectively, could successfully be expressed in E. coli, whereas the murine antiNCAM ScFv version could not be reliably detected. Bispecific CD3 $\times$ VEGFR-2 and CD3 $\times$ NCAM antibodies were expressed in the bispecific single chain and the single chain diabody format. However, the diabody derived from the murine anti-NCAM ScFv could not efficiently be expressed in $E$. coli or in mammalian cells. Significant binding of the CD3 $\times$ NCAM single chain diabody comprising the humanized version of anti-CD3 and humanized version of antiNCAM was efficient to both antigens. Nevertheless, binding of the bispecific single chain version to the NCAM antigen was inefficient in comparison to CD3 binding. In conclusion, the data could indicate that the result of scFv expression in bacteria may be predictive for the chances of success for functional expression of more complex bispecific derivatives.
\end{abstract}

Keywords: Recombinant Antibody;

Single Chain Diabody; Bispecific Antibody;

Protein Expression

\section{INTRODUCTION}

Conventional monoclonal antibodies specifically recognize a single antigen with their $\mathrm{N}$-terminal variable domains. In addition, via their constant C-terminal Fc domain, they are able to activate the complement system and various immune cells such as neutrophils, monocytes, macrophages or dendritic cells. This can lead to inflammatory cytokine expression and even to tissue toxicity. However, for envisioned clinical applications of recombinantly produced antibodies such as immune therapies it is of interest to avoid potential excess inflammatory reactions or cytotoxicity. The C-terminal antibody domain and its potential to arouse side effects could be omitted by novel antibody constructs that combine two binding specificities in this way that they can directly activate and link immune effector cells to target cells of interest [1]. Recombinant bispecific antibodies lack the Fc part and are composed of the variable antigen binding domains only $[2,3]$. One future application of such bispecific antibodies (BsAbs) could be the treatment of cancer by activating and crosslinking cytotoxic $\mathrm{T}$ cells to tumor cells and thereby induce tumor cell death [4]. Due to their reduced size, engineered antibodies that lack the Fc domain are expected to assemble more easily, to be less immunogenic and to be able to penetrate solid tumor tissue more easily than conventional antibodies [5].

The prerequisite for the construction of recombinant bispecific antibodies is the availability of two parental single chain antibodies. DNA encoding antigen-binding domains can be derived from hybridoma cells or from universal phage display libraries [6-8]. BsAbs have been raised against various cancer antigens and successfully 
demonstrated anti-tumor activity in vitro and in vivo [918]. Various formats for bispecific antibodies have been proposed, such as bicistronic diabody expression constructs that express two different peptide chains from a single mRNA and the single chain diabody or bispecific single chain formats. An advantage of the single chain format is that no assembly is required and folding is thought to be more robust since both binding specificities are present in a single polypeptide chain.

Even though BsAbs are already being tested in the clinic, further research is necessary to improve characteristics like the reduction of immunogenicity by humanizing antibodies isolated from other species, by improving the target specificity of novel antibodies that differentiate between protein modifications present only on tumor cells but not on differentiated cells that express the same protein, by cost-effective production, antibody stability in the human circulation and by improving the efficacy in vivo [19]. With respect to full-length antibodies, for in vitro investigations recombinant antigen binding fragments can be expressed with a good success rate - comparatively quickly and with limited efforts even in bacteria [20]. However, for clinical use, due to the absence of inflammatory side products and the humancompatible posttranslational modifications the preferred expression system for therapeutical proteins is mammalian cell cultures. Suitable production cell lines must fulfill multiple requirements such as the absence of endogenous virus production and robust cell growth in suspension cultures in the absence of serum. Few cell lines meet these conditions. Preferred producer cells are human kidney cell lines, hamster cells or murine myeloma cells [21]. Subsequent purification of the recombinant antibodies can efficiently be performed in a single step using affinity chromatography in combination with peptide-tagged antibody [22].

The specific binding capabilities of antibody variable domains can be influenced by the domain positions relative to each other, by amino acid sequences outside of the complementarity determining regions and by the production system. Therefore, the strategy of this study was to generate, to characterize and to compare the functionality of various antibody formats and production systems. The construction, production, purification and antigen binding capabilities of recombinant bispecific antibodies that bind $\mathrm{T}$ cells and either of two tumor-associated antigens were investigated. The tumor antigen neural cell adhesion molecule (NCAM) is expressed on several tumor cells, such as neuroblastoma cells, the second most common malignancy among childhood cancers [23]. The second antigen, vascular endothelial growth factor receptor 2 (VEGFR-2) is expressed on cancer cells and non-tumorigenic cells such as vascular endothelial cells. VEGF directly stimulates cancer cell mitosis and additionally, indirectly supports tumor growth by stimulating blood vessel sprouting to enhance tumor oxygenation and nutrient supply [24-26]. A full length CD3 $\times$ NCAM antibody has previously been shown to induce cytotoxicity of T cells to NCAM expressing tumor cells [16]. CD3 $\times$ NCAM and CD3 $\times$ VEGFR-2 BsAbs were both constructed as single chain antibodies and as single chain diabodies. With the exception of constructs derived from one specific antibody, the BsAb proteins investigated in this study could be expressed in bacteria as well as in mammalian cells, and in addition, they could bind to both cognate antigens expressed on the surface of cells.

\section{MATERIALS AND METHODS}

\subsection{Construction of CD3 $\times$ VEGFR-2 Single Chain Antibody bs2,5 and CD3 $\times$ NCAM Single Chain Antibodies bs1,3 and bs2,4}

The cDNA of the mouse anti-VEGFR-2 scFv A7 was PCR amplified from the pCANTAB5EscFvA7 construct [27]. The fragment was cloned into an expression vector pKozak-Splice that already contained the humanized anti-CD3 scFv UCHT1 as previously described [28]. A C-terminal c-myc epitope and mRNA processing signals were introduced into the cDNA of scFv A7 by three amplification steps using one forward primer V-BspEI

(atccggacaggtgaaactgcaggagtctggacctgagctggtg) and four reverse primers V-rev

(ggggggaagatgaacacactgggggcagccactgtccgtttcagctccagct tggtcccccctccg), universal-rev

(gatcagcttctgctcttcagcagaagggggggaagatgaacacactgggggcagccactgt), universal-rev2

(gagttcaggtcctcttcagagatcagcttctgctcttcagcagaaggggggaag) and universal-rev3

(tactagttatcagtccacagcagagttcaggtcctcttcagagatcagcttctgctc). The final amplicon was cloned via BspEI and SpeI in the expression vector resulting in the following 5 ' -3 ' orientation: (VL-VH) UCHT1-18aa linker-(VH-VL)A7 yielding bs2,5. The 18 amino acid linker between the $\mathrm{scFv}$ fragments was derived from the human IgG elbow region of the CH1 domain [29]. The same strategy was used to construct bs1,3 and bs2,4.

\subsection{Assembly of the CD3 $\times$ VEGFR-2 Single Chain Diabody db2,5 and of the CD3 $x$ NCAM Single Chain Diabodies db1,3 and db2,4}

The coding sequences of VH and VL from OKT3 and UCHT1 were amplified from the cDNA of the hybridoma clone OKT3 and from pCANTAB5EscFv UCHT1, respectively; the cds of VH and VL from scFv A7, ERIC1 and D29 was amplified from pCANTAB5E scFvA7, the cDNA of hybridoma clone ERIC1 and from the pCANTAB5E scFv D29 clone. scFv Fragments in the configu- 
ration $\mathrm{V}_{\mathrm{H}(\mathrm{CD} 3)}-\mathrm{Gly}_{4} \mathrm{Ser}-\mathrm{V}_{\mathrm{L}(\mathrm{NCAM})}$ and $\mathrm{V}_{\mathrm{H}(\mathrm{NCAM})^{-}-\mathrm{Gly}_{4} \text { Ser- }}$ $\mathrm{V}_{\mathrm{L}(\mathrm{CD} 3)}$ and $\mathrm{V}_{\mathrm{H}(\mathrm{CD} 3)^{-}} \mathrm{Gly}_{4}$ Ser- $\mathrm{V}_{\mathrm{L}(\mathrm{VEGFR}-2)}$ and $-\mathrm{V}_{\mathrm{H}(\mathrm{VEGFR}-2)^{-}}$ $\mathrm{Gly}_{4} \mathrm{Ser}-\mathrm{V}_{\mathrm{L}(\mathrm{CD} 3)}$ were generated by assembly extension PCR as described previously [30]. In a second step the inverse $\mathrm{scFv}$ fragments were assembled introducing a $\left(\mathrm{Gly}_{4} \mathrm{Ser}\right)_{3}$-linker between both partners resulting in single chain diabodies with the following configuration: $\mathrm{V}_{\mathrm{H}}$

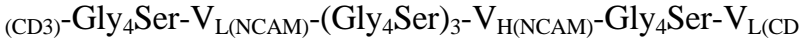
3) and $\mathrm{V}_{\mathrm{H}(\mathrm{CD} 3)}-\mathrm{Gly}_{4} \mathrm{Ser}-\mathrm{V}_{\mathrm{L}(\mathrm{VEGFR}-2)}-\left(\mathrm{Gly}_{4} \mathrm{Ser}\right)_{3}-\mathrm{V}_{\mathrm{H}(\mathrm{VEGFR}-2)^{-}}$ $\mathrm{Gly}_{4} \mathrm{Ser}_{\mathrm{L}} \mathrm{V}_{\mathrm{L}(\mathrm{CD} 3)}$. All assembled PCR products contained a 5' SfiI and a 3' NotI recognition site. Then the PCR products were cloned via SfiI and NotI into the mammalian cell expression vector pSecTag/HygroA (Invitrogen). Using this assembly procedure $\mathrm{db} 1,3$; $d \mathrm{~b} 2,4$ and $\mathrm{db} 2,5$ were obtained.

\subsection{Recombinant Antibody Expression in Bacteria}

For recombinant protein expression in bacteria, the diabodies UCHT1 $\times$ A7, OKT3 $\times$ ERIC1, UCHT1 $\times$ D29, OKT-3 $\times$ ERIC1 single chain antibody and the scFv coding sequences of OKT3, UCHT1, ERIC1 and D29 were cloned in to the $E$. coli expression vector pCANTAB5E (GE Healthcare) using SfiI and NotI sites. After transformation of diabodies, single chain antibody and scFv expression plasmids in E. coli HB2151 recombinant antibody expression was induced at OD600 1.0 with $0.2 \mathrm{mM}$ IPTG and the cells were further cultured for $16 \mathrm{~h}$ at $25^{\circ} \mathrm{C}$ in $100 \mathrm{ml}$ in $2 \times$ YTS medium (16 g/l trypton, $10 \mathrm{~g} / \mathrm{l}$ yeast extract, $5 \mathrm{~g} / \mathrm{l} \mathrm{NaCl}, 0.4 \mathrm{M}$ sucrose). The periplasmatic fraction and the culture supernatant were collected and the proteins separated by SDS-PAGE followed by either silver staining or Western blot analysis [31].

\subsection{Mammalian Cell Culture Procedures}

VEGF-receptor 2 (VEGFR-2) expressing porcine aortic endothelial cell line PAE-KDR or PAE-FUA [32] were cultured in DMEM, 10\% FCS (heat-inactivated; Biochrom AG, Berlin, Germany), 2 mM glutamine (Serva, Heidelberg, Germany), 0.4 mg/ml G418 (Gibco, Serva, Heidelberg, Germany) under standard conditions in a humidified atmosphere with $5 \% \mathrm{CO}_{2}$ at $37^{\circ} \mathrm{C}$. Jurkat cells (ACC-282, DSMZ, Braunschweig, Germany), TE671 and LS cells were grown in RPMI 1640 supplemented with $10 \%$ FCS and $2 \mathrm{mM}$ glutamine. For purification of recombinant db2,5 stable transfected BHK21 cells (ATCC $^{\circledR}$ CCL-10) were grown in serum-free Pro-CHO5 medium (Lonza, Basel, Switzerland) supplemented with $7.5 \mathrm{mM}$ glutamine and $0.8 \mathrm{mg} / \mathrm{ml}$ hygromycin B. For purification of recombinant bs2,5 stable transfected Sp2/0-Ag14 murine myeloma cells (CRL-1581, ATCC) were cultured in serum-free CD Hybridoma Medium (Gibco) with 7.5 $\mathrm{mM}$ glutamine and $1.0 \mathrm{mg} / \mathrm{ml} \mathrm{G} 418$ and cholesterol (250 $\times$ lipid concentrate, Gibco).

\subsection{Expression of CD3 $\times$ VEGFR-2 Single Chain Antibody bs2,5 and CD3 $\times$ NCAM Single Chain Antibodies bs1,3 and bs2,4}

To enhance vector integration the bs2,5 DNA construct was linearized with AhdI (New England Biolabs, Frankfurt/Main, Germany) and stably transfected into Sp2/0Ag14 murine myeloma cells by electroporation at $230 \mathrm{~V}$ and a capacity of $975 \mu \mathrm{F}$ (Gene Pulser, Biorad). Cells were cultured under standard conditions in the presence of $\mathrm{G} 418$ (1 $\mathrm{mg} / \mathrm{ml}$ final concentration) to select stable bs2,5 antibody producing cell clones. The same procedure was used to assemble and express the construct $\left(\mathrm{V}_{\mathrm{L}}-\mathrm{V}_{\mathrm{H}}\right)_{\text {октз}}$-18aa linker- $\left(\mathrm{V}_{\mathrm{H}}-\mathrm{V}_{\mathrm{L}}\right)_{\text {murine NCAM }}$ resulting in bs1,3 and $\left(\mathrm{V}_{\mathrm{L}}-\mathrm{V}_{\mathrm{H}}\right)_{\mathrm{UCHT1}}-18 \mathrm{aa}$ linker- $\left(\mathrm{V}_{\mathrm{H}}-\mathrm{V}_{\mathrm{L}}\right)_{\text {humanized NCAM }}$ resulting in bs2,4.

\subsection{Generation of Cells Expressing the CD3 $\times$ VEGFR-2 Single Chain Diabody db2,5 or the CD3 $\times$ NCAM Single Chain Diabodies db1,3 or db2,4}

DNA of the diabody expression plasmids was linearized with the restriction enzyme AhdI and then transfected into BHK cells by the calcium phosphate co-precipitation method [33]. Selection of stable producing cells was performed in the presence of $800 \mu \mathrm{g} / \mathrm{ml}$ hygromycin B in the cell culture medium.

\subsection{Production of CD3 $\times$ VEGFR-2 Antibody bs2,5 in Murine Myeloma Cells}

For adaption to serum-free culture, $2.2 \times 10^{6}$ cells were cultured in a T75 flask in $25 \mathrm{ml}$ IMDM with 3\% FCS. The preadapted cells were then cultured to a cell density of $5 \times 10^{5}$ cells $/ \mathrm{ml}$ in $25 \mathrm{ml}$ serum-free CD Hybridoma Media (Gibco, Invitrogen) with $7.5 \mathrm{mM}$ glutamine and 1 $\mathrm{mg} / \mathrm{ml} \mathrm{G} 418 ; 1 / 250 \mathrm{v} / \mathrm{v}$ cholesterol lipid concentrate. For antibody production, $2 \times 10^{5}$ cells $/ \mathrm{ml}$ in $75 \mathrm{ml}$ medium per T175 flask were inoculated. Cell culture supernatants (600 ml total volume) were harvested, filtered and dialyzed against PBS pH 8.0. The supernatants were centrifuged and filtered to remove insoluble precipitates. The recombinant antibody was purified using an anti-c-myc agarose column (Sigma-Aldrich).

\subsection{Production of CD3 $\times$ VEGFR-2 Antibody db2,5 in BHK21 Cells}

BHK21 cells were stably transfected with DNA of the plasmid pSecTag/HygroA (Invitrogen) containing the coding sequence of the diabody $\mathrm{db} 2,5$. For the production of db2,5 in BHK21, the cells were cultured in Pro-CHO 5 media supplemented with $7.5 \mathrm{mM}$ glutamine and 0.8 
$\mathrm{mg} / \mathrm{ml}$ hygromycin B. $280 \mathrm{ml}$ of cell culture supernatant from eight T175 flasks were harvested and dialyzed against $50 \mathrm{mM} \mathrm{NaH} \mathrm{PO}_{4} ; 300 \mathrm{mM} \mathrm{NaCl}$; pH 8.0 at $4^{\circ} \mathrm{C}$. The dialyzed cell culture supernatants were purified using $\mathrm{Co}^{2+}$ based affinity resins.

\subsection{Purification of the CD3 $\times$ VEGFR-2 Antibody bs2,5}

The bispecific antibody bs2,5 was produced in Sp2/0Ag14 murine myeloma cells and secreted in the supernatant. A $5 \mathrm{ml}$ column (MoBiTec) was packed with 1.5 $\mathrm{ml}$ anti-c-myc agarose. The column was washed with 7.5 ml elution buffer (0.1 M ammonium hydroxide, $\mathrm{pH} 11.2$ and $7.5 \mathrm{ml}$ PBS binding buffer, $\mathrm{pH}$ 8.0). The flow-through was reloaded three times. The column was washed until the flow-through solution reached a lower OD280 nm of 0.01 . bs2,5 was eluted using $50 \mathrm{mM} \mathrm{NaH} \mathrm{PO}_{4} ; 300 \mathrm{mM}$ $\mathrm{NaCl}$; $250 \mathrm{mM}$ imidazole; $\mathrm{pH}$ 8.0. $1 \mathrm{ml}$ fractions were collected, neutralized by the addition of $90 \mu \mathrm{l} 1 \mathrm{~N}$ acetic acid and dialyzed against PBS pH 7.0 at $4^{\circ} \mathrm{C}$. Protein concentrations were determined using the Micro BCA assay method (Thermo Fisher Scientific) [34].

\subsection{SDS PAGE and Immune-Blot Analysis}

Proteins were separated using 10\% SDS-PAGE. Proteins were fixed with $40 \%$ ethanol; $10 \%$ acetic acid and were silver stained according to the manufacturer's specifications (GE Healthcare). Alternatively, proteins were transferred to polyvinylidene fluoride (PVDF) membranes (BioRad, Hercules, USA) using the SemiDry method [35]. Membranes were blocked for one hour in blocking buffer (5\% Blotting Grad Blocker Non-Fat Dry Milk in PBS; BioRad) at room temperature (RT). Subsequently, the membranes were incubated with a primary antibody (mouse anti-c-myc (9E10): sc-40, Santa Cruz, Heidelberg, Germany; His-Tag monoclonal antibody, Merck Millipore, Darmstadt, Germany or E tag antibody, GE Healthcare); all 1:1.000 diluted in $3 \mathrm{ml}$ of 2.5\% blocking buffer) overnight at RT. The membranes were washed three times with PBS/0.05\% Tween 20, then incubated with a peroxidase labeled secondary antibody in $3 \mathrm{ml}$ of $2.5 \%$ blocking buffer for one hour at RT (peroxidase-conjugated AffiniPure goat anti-mouse IgG $(\mathrm{H}+\mathrm{L})$, Dianova; diluted 1:1.000). Then, the membrane was washed three times with PBS/0.05\% Tween 20 and once with distilled water and subsequently the membrane was dried. The activity of peroxidase was visualized using DAB reaction according to the manufacturer's specifications (SIG MAFAST ${ }^{\mathrm{TM}}$ DAB; Sigma-Aldrich).

\subsection{Purification of Bispecific CD3 $\times$ VEGFR-2 Diabody db2,5}

The bispecific antibody db2,5 was produced in BHK21 cells and secreted into the cell culture supernatant. The purification of serum-free ProCHO 5 supernatant was performed with TALON ${ }^{\mathrm{TM}}$ Superflow Metal $\left(\mathrm{Co}^{2+}\right)$ affinity resins (Clontech). A $5 \mathrm{ml}$ column with $1 \mathrm{ml}$ resin volume was equilibrated with binding buffer containing $5 \mathrm{mM}$ imidazole. $280 \mathrm{ml}$ of cell culture supernatant was dialyzed in $50 \mathrm{mM} \mathrm{NaH} \mathrm{PO}_{4} ; 300 \mathrm{mM} \mathrm{NaCl}$; pH 8.0. The flow-through was loaded on the column five-times in a row. The column was washed using $10 \mathrm{ml}$ binding buffer with $5 \mathrm{mM}$ imidazole and the bound protein db2,5 was eluted with $10 \mathrm{ml}$ elution buffer $\left(50 \mathrm{mM} \mathrm{NaH} \mathrm{PO}_{4}, 300\right.$ $\mathrm{mM} \mathrm{NaCl} ; 250 \mathrm{mM}$ imidazole $\mathrm{pH}$ 8.0). Fractions of $1 \mathrm{ml}$ were collected and dialyzed three times against PBS $\mathrm{pH}$ 7.0 at $4^{\circ} \mathrm{C}$. Determination of protein concentration and protein purity with silver stained SDS-PAGEs or by Western blot analysis were carried out as described for the purification of bs2,5 antibody.

\subsection{Antigen Binding of CD3 $\times$ VEGFR-2 Antibodies bs2,5 and db2,5}

To examine the binding of bispecific antibodies bs2,5 and $\mathrm{db} 2,5$, different antigen expressing cell lines were used: The VEGFR-2 expressing PAE-KDR, the VEGFR-1 expressing PAE-FLT-1, Jurkat and the NCAM expressing TE671 cell line. $10^{5}$ cells of each cell type were used in $100 \mu \mathrm{L}$ FACS buffer (PBS; 2\% FCS) per well of a 96-well round bottom plate. The antibodies were diluted in a volume of $40 \mu \mathrm{l}$ PBS and added to the respective wells so that concentrations resulted in total of 0.2 $\mu \mathrm{g} / \mathrm{ml}$ of each antibody. The plate was incubated for 30 min at $4^{\circ} \mathrm{C}$, centrifuged (1000 g; $5 \mathrm{~min} ; 4^{\circ} \mathrm{C}$ ) and the supernatant was discarded. After one wash step with 200 $\mu$ FACS buffer, the cells were incubated either with primary anti-c-myc antibody 1:200 diluted in $100 \mu \mathrm{l}$ of FACS buffer or with buffer only for $30 \mathrm{~min}$ at $4^{\circ} \mathrm{C}$. Cells incubated with only the second phycoerythrin (PE) labeled antibody served as negative controls. The solutions were removed via centrifugation and one wash step as mentioned above. The second PE labeled antibody (goat anti-mouse IgG $\mathrm{F}_{\mathrm{c}}$-RPE, Dianova, Hamburg, Germany, 1:200 diluted in $100 \mu \mathrm{l}$ of FACS buffer) was added and wells with negative samples were only filled with buffer. After a 30 min incubation period at $4^{\circ} \mathrm{C}$, the cells were washed once and resuspended in $200 \mu \mathrm{L}$ FACS buffer. Dead cells were stained with PI (Applichem, Darmstadt, Germany). 20000 antibody stained cells per sample were analyzed with flow cytomety (BD FACSCalibur, BD Bioscience, San Jose, USA using the software BD CellQuest ${ }^{\mathrm{TM}}$ Pro, BD Bioscience). Viable cells were gated after staining with PI and the emission of each fluorochrome was compensated using the software FlowJow (Tree Star Inc., Ashland, USA).

CD3 expressing Jurkat or NCAM expressing TE671 
cells were incubated with the supernatant of db2,4 expressing BHK cell cultures. Cell-bound db2,4 antibody was detected with primary mouse anti-c-myc and goat anti-mouse IgG $F_{c}-R-P E$ labeled secondary antibody. As a control, cells were incubated with isotype control mouse antibodies and secondary goat anti-mouse antibody. VEGFR-2 expressing PAE-KDR, CD3 expressing Jurkat and VEGFR-1 expressing PAE-FLT-1 control cells were incubated with $0.2 \mu \mathrm{g} / \mathrm{ml}$ bs2,5 antibody. Cellbound bs2,5 antibody was detected with primary mouse Anti-c-myc and goat anti-mouse IgG Fc-RPE labeled secondary antibody. As control, $1 \mu \mathrm{g} / \mathrm{ml}$ bs2,5 antibody was incubated with cells and detected only with goat antimouse IgG Fc-RPE labeled secondary antibody. The binding of db2,5 to VEGFR-2 ${ }^{+}$PAE-KDR, $\mathrm{CD}^{+}{ }^{+}$Jurkat and VEGFR- $1^{+}$PAE-FLT-1 control cells were examined using $0.2 \mu \mathrm{g} / \mathrm{ml}$ recombinant antibody db2,5. Binding of $\mathrm{db} 2,5$ antibody to antigen expressing cells were detected as described above with primary anti-c-myc antibody and goat antimouse IgG $\mathrm{F}_{\mathrm{c}}$-RPE labeled secondary antibody. For further experimental details see figure legends.

\section{RESULTS}

\subsection{Bacterial Expression of Parental scFv Constructs and Bispecific Formats Derived Thereof}

To generate antibodies that could simultaneously bind to $\mathrm{T}$ cells expressing CD3 and to tumor cells expressing either the NCAM or VEGFR-2 molecule on the cell surface several different bispecific antibodies were constructed (Figure 1). An overview of the origin of the parental antibodies and of the bispecific derivatives used in this study is given in Table $\mathbf{1}$.

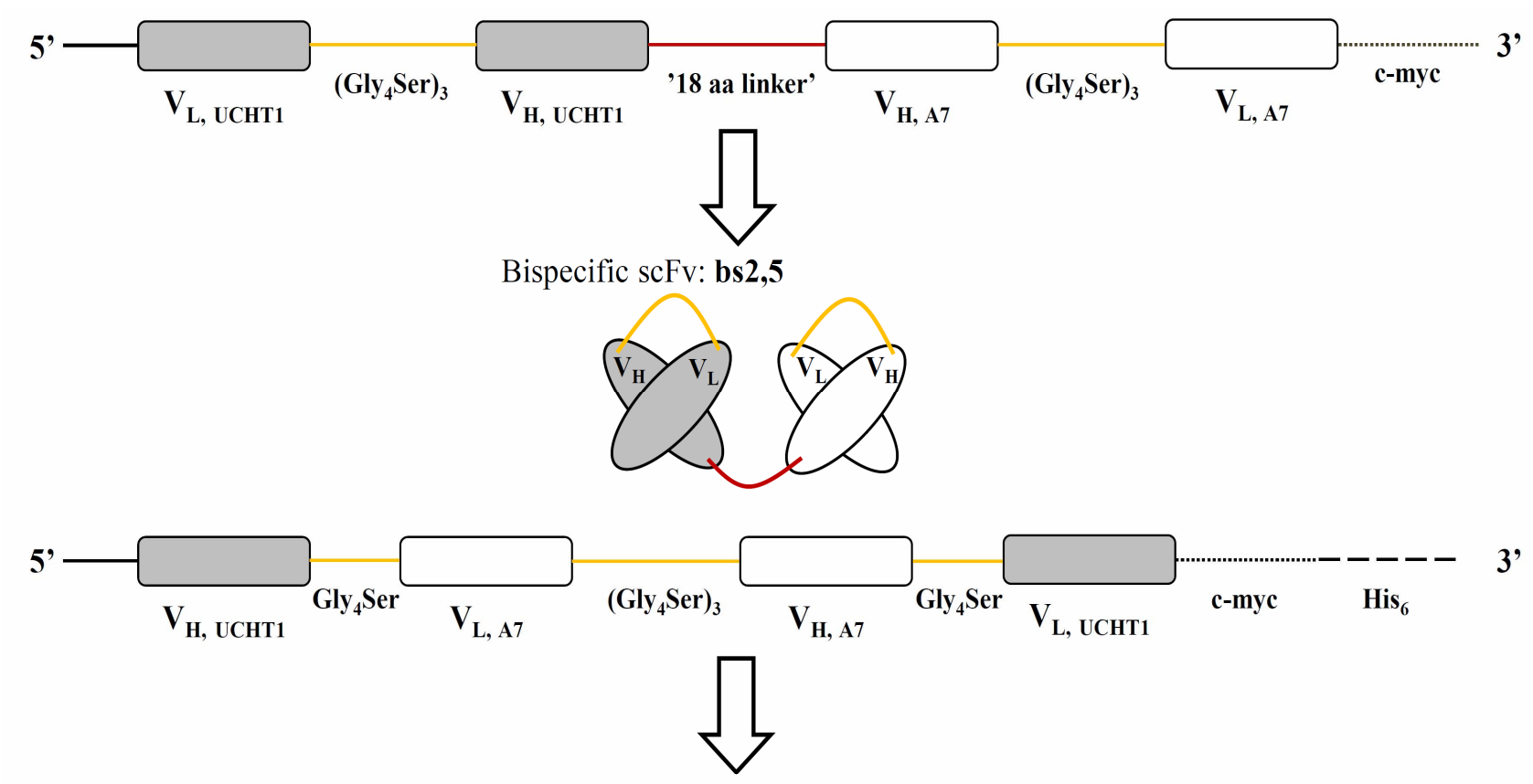

Bispecific single chain diabody: $\mathbf{d b 2 , 5}$
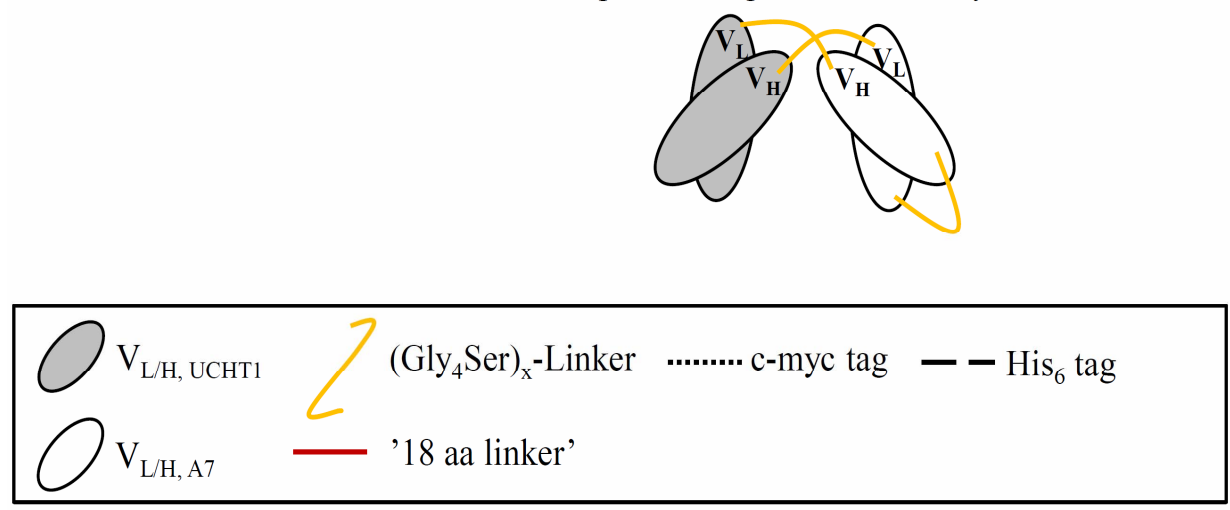

Figure 1. Structure of bispecific single chain variable fragment (BsscFv) and diabody (db) constructs. The arrangements of the DNA encoding the variable VH and VL domains and the structures of the resulting protein products are indicated. 
Table 1. Recombinant antibody constructs and expression.

\begin{tabular}{|c|c|c|c|c|c|c|c|c|c|}
\hline Construct & Antigen specificity & Parental constructs & Species $^{*}$ & Format & Tag & $\begin{array}{l}\text { Expression } \\
\text { system }\end{array}$ & $\begin{array}{l}\text { Protein } \\
\text { expression }\end{array}$ & $\begin{array}{l}\text { CD3/ NCAM or } \\
\text { VEGFR binding }\end{array}$ & Reference \\
\hline $\mathrm{db} 2,4$ & CD3xNCAM & UCHT1xD29 & $\mathrm{h}$ & scdb & myc-his & E. coli & + & $+/+$ & This study \\
\hline $\mathrm{db} 1,3$ & CD3xNCAM & OKT3xERIC1 & $\mathrm{m}$ & scdb & myc-his & E. coli & n.d. & & This study \\
\hline bs1,3 & CD3xNCAM & OKT3xERIC1 & $\mathrm{m}$ & bsscFv & myc & E. coli & n.d. & & This study \\
\hline $\mathrm{db} 2,5$ & CD3xVEGFR-2 & UCHT1xA7 & hxm & scdb & myc-his & E. coli & + & $+/+$ & This study \\
\hline $\mathrm{db} 1,3$ & CD3xNCAM & OKT3xERIC1 & $\mathrm{m}$ & scdb & myc-his & BHK21 & n.d. & & This study \\
\hline $\mathrm{db} 2,4$ & CD3xNCAM & UCHT1xD29 & h & scdb & myc-his & BHK21 & + & $+/+$ & This study \\
\hline $\mathrm{db} 2,5$ & CD3xVEGFR-2 & UCHT1xA7 & hxm & $\operatorname{scdb}$ & myc-his & BHK21 & + & $+/+$ & This study \\
\hline bs1,3 & CD3xNCAM & OKT3xERIC1 & $\mathrm{m}$ & bsscFv & myc & $\mathrm{SP} 2 / 0$ & & & This study \\
\hline bs2,4 & CD3xNCAM & UCHT1xD29 & $\mathrm{h}$ & bsscFv & myc & $\mathrm{SP} 2 / 0$ & + & $+/+$ & This study \\
\hline bs2,5 & CD3xVEGFR-2 & UCHT1xA7 & hxm & bsscFv & myc & $\mathrm{SP} 2 / 0$ & + & $+/+$ & This study \\
\hline OKT3 & CD3 & & $\mathrm{m}$ & sc & & E. coli & + & & This study \\
\hline OKT3 & CD3 & & $\mathrm{m}$ & sc & & BHK21 & + & & This study \\
\hline UCHT1 & CD3 & & h & sc & & E. coli & + & & This study \\
\hline ERIC1 & NCAM & & $\mathrm{m}$ & sc & & E. coli & n.d. & & This study \\
\hline ERIC1 & NCAM & & $\mathrm{m}$ & sc & & BHK21 & n.d. & & This study \\
\hline D29 & NCAM & & $\mathrm{h}$ & sc & & E. coli & + & & This study \\
\hline D29 & NCAM & & h & sc & & BHK21 & + & & This study \\
\hline A7 & VEGFR-2 & & $\mathrm{m}$ & sc & & E. coli & + & & This study \\
\hline A7 & VEGFR-2 & & $\mathrm{m}$ & sc & & BHK21 & + & & This study \\
\hline OKT3 & CD3 & & $\mathrm{m}$ & \multicolumn{2}{|c|}{ Monoclonal } & & & & {$[36]$} \\
\hline UCHT1 & CD3 & & h & \multicolumn{2}{|c|}{ Monoclonal IgG2a } & & & & {$[28]$} \\
\hline ERIC1 & NCAM & & $\mathrm{m}$ & \multicolumn{2}{|c|}{ Monoclonal } & & & & [37] \\
\hline D29 & NCAM & & $\mathrm{h}$ & \multicolumn{2}{|c|}{ ERIC1 derivative } & & & & [38] \\
\hline A7 & VEGFR-2 & & $\mathrm{m}$ & \multicolumn{2}{|c|}{ phage display } & & & & {$[27]$} \\
\hline
\end{tabular}

The parental anti-CD3 scFv constructs OKT3 and the humanized UCHT1 as well as the anti-NCAM scFv ERIC1 and its humanized derivative D29 were expressed in $E$. coli. Proteins present in the culture supernatant and from the periplasmatic fraction were separated by SDS-PAGE and stained by decoration with tag-specific antibodies. The expression of scFv OKT3, scFv UCHT1 and scFv D29 in the periplasm was within the expected range (Figure 2(a), lanes 2 and $\mathrm{B}$, clone 1-4) compared to the marginal expression levels of scFv ERIC1 (Figure 2(b), lane 3). Expression of the OKT3 $\times$ ERIC1 diabody was neither detectable in the periplasmatic fraction nor in the culture supernatant (Figure 3, lane 2). The scFv UCHT1 and UCHT1 $\times$ A7 diabody could be expressed in the periplasm of E. coli bacteria (Figure 4, lanes 7 and
8 , respectively). Therefore, with the exception of the antiNCAM antibody ERIC1 derivatives all bispecific proteins examined could be expressed in the periplasm of bacteria.

\subsection{Purification of CD3 $\times$ VEGFR-2 Antibody bs2,5 from Myeloma Cells}

For potential animal studies or future clinical applications mammalian cell expression would be desirable to avoid the danger of immune reactive bacterial contaminations. Murine bs2,5 producer cells were grown in serum-free medium. The bs2,5 protein present in the culture supernatant was purified by anti-myc affinity column chromatography and characterized by SDS PAGE and by 


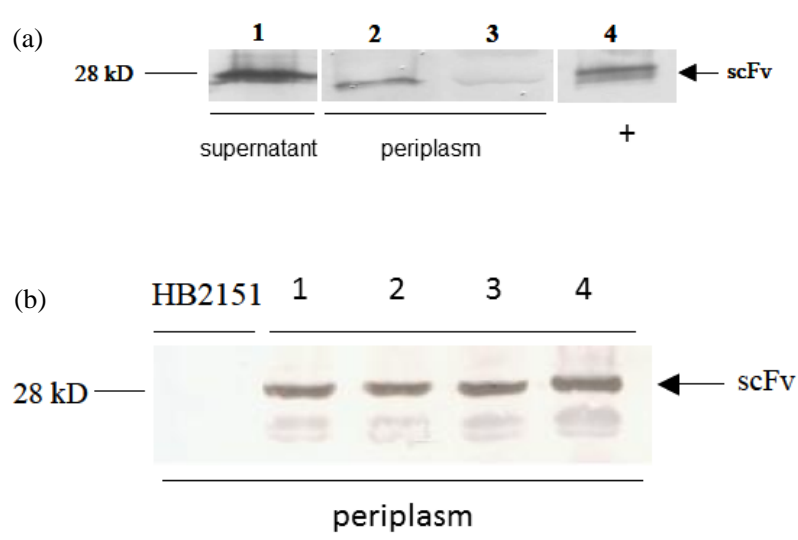

Figure 2. Expression of scFv OKT3, ERIC1 and D29 in bacteria. E. coli HB2152 transformed with plasmid DNA encoding the antibody constructs indicated were cultured and media supernatant and periplasmatic fractions were analyzed by the Western Blotting procedure. The recombinant proteins were detected by hybridization with mouse anti-E-tag antibody, followed by incubation with peroxidase labeled goat anti-mouse antibody. (a) scFv OKT3 expressed in E. coli. lane 1, culture supernatant; lane 2, periplasmatic fraction; lane 3, periplasmatic fraction of ERIC1 expressing $E$. coli; lane 4, purified scFvA7. (b) Periplasmatic fraction of native E. coli HB2152 and of scFvD29 expressing clones 1 to 4 . The position of the 28 $\mathrm{kDa}$ protein marker and the expected position of the scFv protein are indicated.

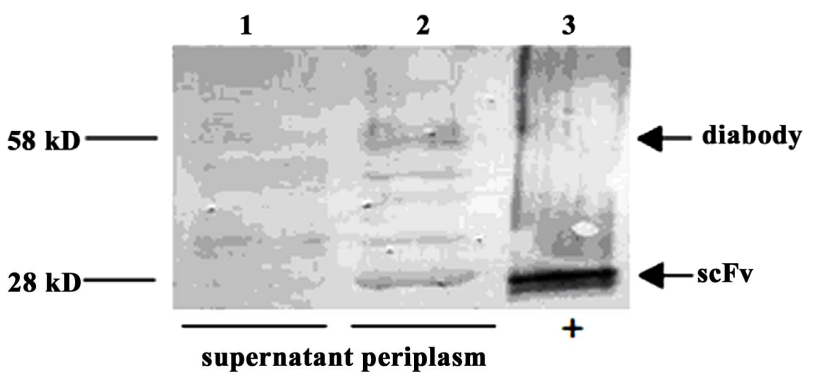

Figure 3. Expression of the OKT3 $x$ ERIC1 diabody db1,3 in bacteria. Cell culture supernatant and periplasmic fractions were characterized as described in Figure 2. Lane 1, cell culture supernatant; lane 2, periplasmatic fraction; lane 3 , affinity purified scFv A7.

immunoblot analysis. The recombinant protein could be detected in the load and in the eluted fractions but not in the flow-through or wash fractions (Figure 5 and data not shown). Overall, $49 \mu \mathrm{g}$ of affinity-purified bs2,5 were obtained from $600 \mathrm{ml}$ cell culture supernatant. This data showed that the protein was secreted into the cell culture medium and could be visualized as a single band by silver stained PAGE.

\subsection{Purification of CD3 $\times$ VEGFR-2 Bispecific Antibody db2,5}

Since the anti-c-myc affinity columns were limited in the protein binding capacity the His-tagged diabody db2,5

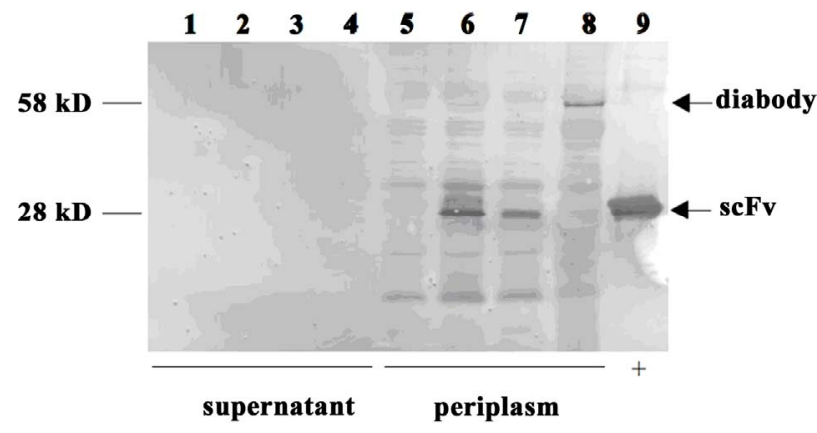

Figure 4. Expression of scFv UCHT1 and UCHT1 $\times$ A7 diabody db2,5 in bacteria. Antibodies were expressed and analyzed as described in the legend of Figure 2. Lane 1, E. coli HB2152; lane 2, culture supernatant from E. coli HB2152 transformed with DNA of the scFv A7 expression plasmid; lane 3, supernatant scFv UCHT1; lane 4, supernatant UCHT1 × A7 diabody, lane 5, periplasmatic fraction of E. coli HB2152; lane 6, periplasmatic fraction of scFv A7 (positive control); lane 7, periplasmatic fraction of scFv UCHT1; lane 8, periplasmatic fraction of UCHT1 $\times$ A7 diabody; lane 9, affinity purified scFv A7.

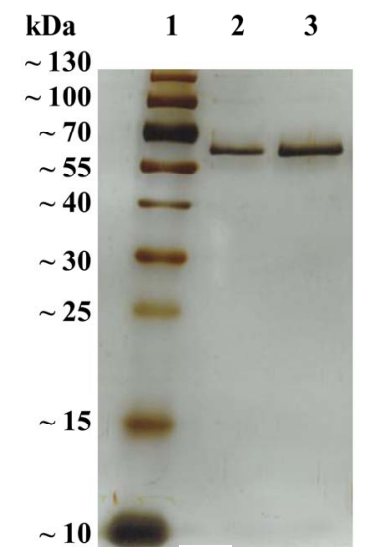

(a)

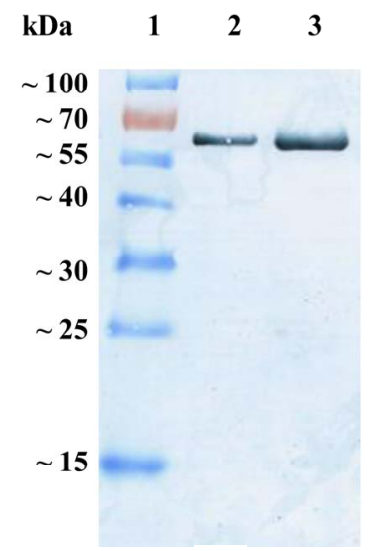

(b)
Figure 5. Analysis of affinity purified CD3 $\times$ VEGFR-2 bispecific antibody bs2,5. bs2,5 expressing myeloma cell culture supernatant was purified with a $1.5 \mathrm{ml}$ anti-c-myc agarose affinity column and eluted fractions with the highest protein concentrations were combined. (a) Proteins se- parated by SDS-PAGE and silver stained. Lane 1, molecular weight markers; lane 2, $0.5 \mu \mathrm{g}$ of purified bs2,5; lane 3, $1 \mu \mathrm{g}$ of bs2,5, (b) Western blot immunoassay: 0.5 $\mu \mathrm{g}$ and $1 \mu \mathrm{g}$ of purified bs2,5 shown in A were blotted onto a PVDF membrane and recombinant bs2,5 protein was detected using mouse anti-c-myc antibody and peroxidase conjugated AffiniPure goat anti-mouse IgG antibodies. Lane 1, molecular weight markers; lane 2, $0.5 \mu \mathrm{g}$ bs2,5; lane 3, $1.0 \mu \mathrm{g}$ bs2,5.

protein was purified using either $\mathrm{Ni}^{2+}$-NTA agarose or $\mathrm{TALON}^{\mathrm{TM}}$ Superflow Metal $\left(\mathrm{Co}^{2+}\right)$ affinity resins. In both cases, a band corresponding to the expected molecular weight of $56 \mathrm{kDa}$ was detected by immuno-blot analysis with anti-His antibody, indicating the binding of $\mathrm{db} 2,5$ to either of the two resins (data not shown). 
However, in comparison to the $\mathrm{Ni}^{2+}$-NTA agarose the $\mathrm{Co}^{2+}$ purification protocol appeared more efficient (not shown). Subsequently, db2,5 in the cell culture supernatant was purified with a $\mathrm{Co}^{2+}$ affinity column.

The purity and identity of the recombinant antibody was confirmed with silver stained SDS-PAGE and by immunoblot analysis (Figure 6). The db2,5 could be isolated in a homogeneous form without any apparent degradation products.

\subsection{Binding of CD3 $\times$ NCAM Antibody db2,4 to CD3 and NCAM Antigen Expressing Cells}

The binding of the bispecific db2,4 antibody present in the cell culture supernatant to CD3 and NCAM was tested with $\mathrm{CD}^{+}$(Jurkat) or $\mathrm{NCAM}^{+}$(TE671) expressing cells, respectively. The diabody binds nearly to $100 \%$ of both living, gated cell types (Figures 7(a) and (b)).

No binding was detected to the NCAM negative LS cells and to VEGFR-2 expressing PAE/KDR cells (Figures 7(c) and (d)). This result indicates that comparatively low amounts of db2,4 antibody could efficiently label both CD3 and NCAM expressing cells.

\subsection{Binding of CD3 $\times$ VEGFR-2 Antibody bs2,5 to CD3 and VEGFR-2 Expressing Target Cells}

The binding of the bispecific bs2,5 antibody to the two cognate antigens was tested with $\mathrm{CD}^{+}$or VEGFR-2 ${ }^{+}$expressing cells, respectively. This antibody binds to $50 \%$ of the VEGFR-2 $2^{+}$cells and to $76 \%$ of the $\mathrm{CD}^{+}$cells (Figures 8(a) and (b), black lines).

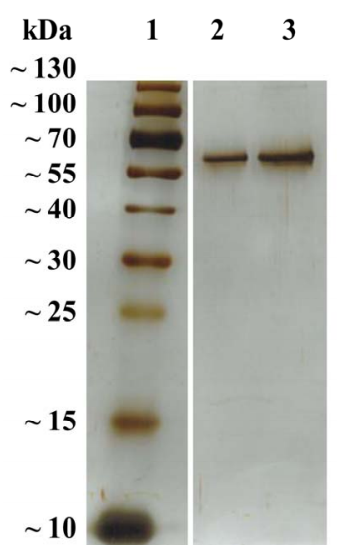

(a)

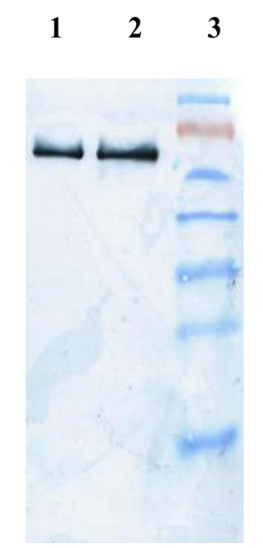

(b)
Figure 6. Purification of CD3 $\times$ VEGFR-2 antibody db2,5 db2,5 antibody was purified by $\mathrm{Co}^{2+}$ affinity chromatography. The proteins were separated by SDS-PAGE and silver stained (a). Lane 1, Molecular weight markers; lane 2, $0.5 \mu \mathrm{g} \mathrm{db} 2,5$; lane 3, $1.0 \mu \mathrm{g} \mathrm{db}$,5. (b) Immunoblot as described in Figure 5. Lane 1, molecular weight markers; lane 2, $0.5 \mu \mathrm{g}$ bs2,5; lane 3, $1.0 \mu \mathrm{g}$ bs 2,5 .
No binding of bs2,5 to the control cell line was detected (Figure 8(c), black graph). These results confirmed the specific binding of bs2,5 antibody to VEGFR-2 ${ }^{+}$and $\mathrm{CD}^{+}$cells.

\subsection{Binding of CD3 $\times$ VEGFR-2 Antibody db2,5 to CD3 and VEGFR-2 Expressing Cells}

The binding of db2,5 to VEGFR-2 or CD3 antigens expressed on mammalian cells was detected by FACS analysis (Figures 9(a) and (b), black graphs). The recombinant antibody db2,5 reacted with $66 \%$ of living, gated VEGFR-2 ${ }^{+}$cells and with $76 \%$ of $\mathrm{CD3}^{+}$cells (Figures 9(a) and (b), Jurkat and PAE-KDR cells).

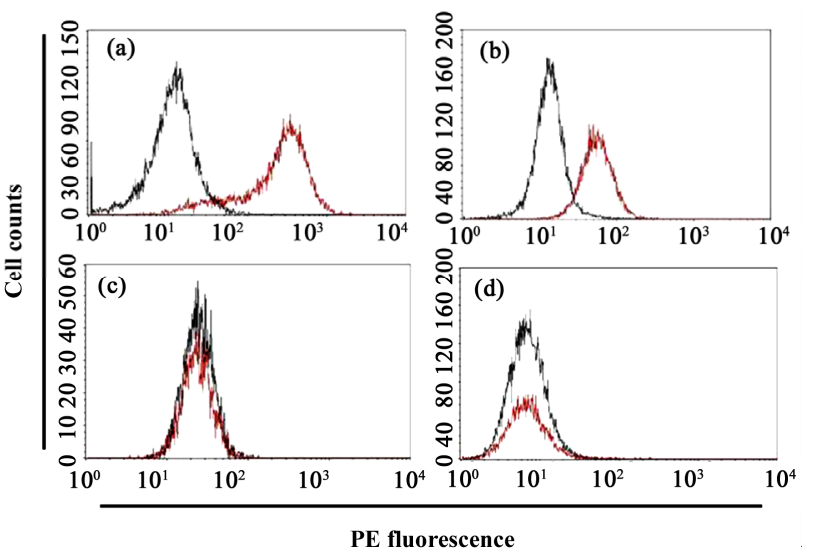

Figure 7. Binding of CD3 $\times$ NCAM antibody db2,4 to CD3 and NCAM expressing target cells. FACS analysis of CD3 (A) or NCAM (B) expressing cells after incubation with the supernatant of db2,4 expressing BHK cell cultures. Cell-bound $\mathrm{db} 2,4$ antibody was detected with mouse anti-c-myc antibody and goat anti-mouse IgG $\mathrm{F}_{\mathrm{C}}$-R-PE labeled antibody (red line). Cells incubated with isotype control mouse antibodies and secondary goat anti-mouse antibody served as a control (black line). LS (C) cells and PAE/KDR cells (D) that did not express CD3 or NCAM were analyzed in the same way.

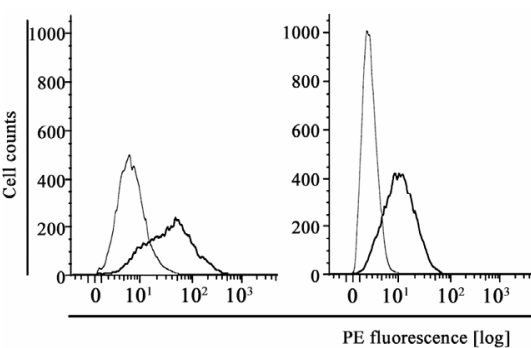

(a)

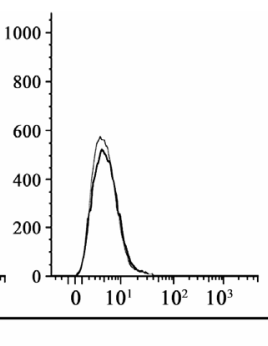

(c)
Figure 8. Binding of CD3 $\times$ VEGFR-2 antibody bs2,5 to CD3 and VEGFR-2 expressing cells. Cells expressingVEGFR-2 (A), CD3 (B) or VEGFR-1 (C) were incubated with affinity purified bs2,5 antibody produced in murine myeloma cells. Cell-bound bs2,5 antibody was detected with primary mouse anti-c-myc and goat anti-mouse IgG $\mathrm{F}_{\mathrm{c}} \mathrm{R}$ PE labeled secondary antibody. Cell-bound bs2,5 antibody was detected with (black) or without (grey) primary antibody. 


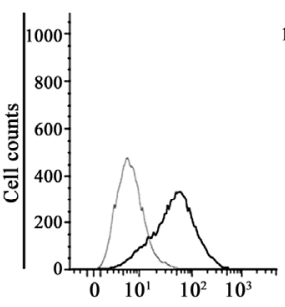

(a)

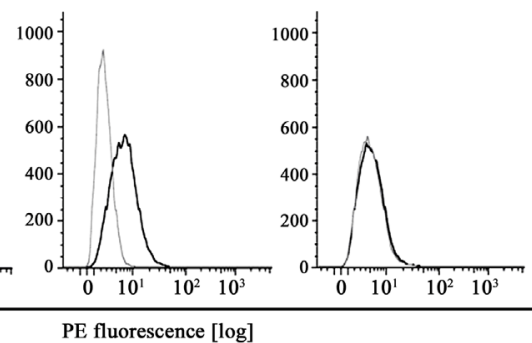

(b)

(c)
Figure 9. Analysis of CD3 $\times$ VEGFR-2 antibody db2,5 binding to CD3 and VEGFR-2 expressing cells. The binding of affinity purified db2,5 antibody produced in BHK cells to VEGFR-2 (a), CD3 (b) or VEGFR-1 (c) expressing cells was examined as described in the legend of Figure 8. Cells were stained either with (black) or without (grey) primary antibody and with PE labeled secondary antibody.

\section{DISCUSSION}

Bispecific antibodies are preferentially investigated for their potential use in cancer immunotherapy due to their high potential to activate $\mathrm{T}$ cell cytotoxicity whereas conventional antibodies solely activate cells primarily of the monocytic family that express Fc receptors. Much remains to be investigated to improve the clinical efficacy. On the one hand, there is a considerable effort required to obtain suitable parental monospecific antibodies with appropriate specificities, to isolate the DNA sequences encoding the binding domains, to humanize the relevant amino acid sequences and to assemble the binding domains.

On the other hand, these manipulations may result in a reduced or even ineffective binding to the respective antigens. Even if the resulting protein is effective in vitro, short half-lives in the human circulation, cross reactivity with normal cells expressing the target antigen or ineffective access to the tumor cells in vivo may limit the clinical success. To further investigate this approach novel bispecific antibodies and their respective monospecific precursors were cloned and expressed in bacteria and mammalian cells. In addition to antibody sequences of murine origin, humanized versions that are expected to be less immunogenic in patients were constructed. Here, with the exception of the ERIC1 construct, all monospecific and bispecific constructs in combination with either bacterial or mammalian expression systems yielded useful amounts of apparently intact and fully functional recombinant antibodies. Even though in bacteria full length antibodies cannot be properly expressed, assembled and folded, the folding of the functional single chain constructs appeared more robust and they could be expressed in either bacteria or mammalian cells. Binding of db2,5 antibody to PAE-FLT-1 cells that did not express CD3 or VEGFR-2 was not detected (Figure 9(c)). These results indicated bispecific binding of $\mathrm{db} 2,5$ antibodies to
VEGFR-2 ${ }^{+}$cells and to $\mathrm{CD}^{+}$cells. Interestingly, the scFv domain ERIC1 could not be expressed satisfactorily in bacteria. Similarly, it could not be expressed as a bivalent construct in either bacteria or mammalian cells. This could suggest that the folding of this domain was distorted in the scFv fragment and in all recombinant derivatives thereof that were investigated in this study. One explanation may be that the functionality of this binding site is sensitive to changes in the surrounding peptide sequences. This idea is supported by the different properties of individual constructs of D29, the humanized derivative of ERIC1. D29 could be expressed as a scFv in bacteria and binding to NCAM could be demonstrated (data not shown). Similarly, both bispecific single chain and single chain diabody UCHT1 $\times$ D29 derivatives of D29 could be expressed in mammalian cells. However, whereas the scFv D29 and the scdb bound to the NCAM antigen, only weak binding of the corresponding bispecific single chain antibody could be detected (data not shown). It could therefore be envisioned, that by optimization of the linker sequences or by in vitro mutagenesis and affinity selection the proper expression and binding could be restored $[7,39]$. The bispecific CD3 $\times$ VEGFR-2 in the single chain and diabody format could be expressed in bacteria and mammalian cells and both products showed robust binding to both antigens. Therefore, these molecules appear promising for further evaluation in cell culture cytotoxicity assays and in appropriate animal tumor models.

\section{ACKNOWLEDGEMENTS}

We thank Ms. Astrid Hans for excellent technical assistance. We kindly acknowledge the financial support of AK by a grant of the ClottenStiftung, Freiburg, Germany. PPM was supported by the Deutsche Forschungsgemeinschaft DFG grant SFB599.

\section{REFERENCES}

[1] Holliger, P. and Hudson, P.J. (2005) Engineered antibody fragments and the rise of single domains. Nature Biotechnology, 23, 1126-1136. doi:10.1038/nbt1142

[2] Buhler, P., Wolf, P., Gierschner, D., Schaber, I., Katzenwadel, A., Schultze-Seemann, W., Wetterauer, U., Tacke, M., Swamy, M., Schamel, W.W. and Elsasser-Beile, U. (2008) A bispecific diabody directed against prostatespecific membrane antigen and CD3 induces T-cell mediated lysis of prostate cancer cells. Cancer Immunology, Immunotherapy, 57, 43-52. doi:10.1007/s00262-007-0348-6

[3] Baeuerle, P.A. and Reinhardt, C. (2009) Bispecific T-cell engaging antibodies for cancer therapy. Cancer Research, 69, 4941-4944. doi:10.1158/0008-5472.CAN-09-0547

[4] Thakur, A. and Lum, L.G. (2010) Cancer therapy with bispecific antibodies: Clinical experience. Current Opinion of Molecular Therapy, 12, 340-349. 
[5] Beckman, R.A., Weiner, L.M. and Davis, H.M. (2007) Antibody constructs in cancer therapy: protein engineering strategies to improve exposure in solid tumors. Cancer, 109, 170-179. doi:10.1002/cncr.22402

[6] Toleikis, L. and Frenzel, A. (2012) Cloning single-chain antibody fragments (ScFv) from hyrbidoma cells. $\mathrm{Me}$ thods of Molecular Biology, 907, 59-71.

[7] Hoogenboom, H.R. (2005) Selecting and screening recombinant antibody libraries. Nature Biotechnology, 23, 11051116. doi:10.1038/nbt1126

[8] Bradbury, A.R., Sidhu, S., Dübel, S. and McCafferty, J. (2011) Beyond natural antibodies: The power of in vitro display technologies. Nature Biotechnology, 29, 245-254. doi:10.1038/nbt.1791

[9] Amann, M., D’Argouges, S., Lorenczewski, G., Brischwein, K., Kischel, R., Lutterbuese, R., Mangold, S., Rau, D., Volkland, J., Pflanz, S., Raum, T., Munz, M., Kufer, P., Schlereth, B., Baeuerle, P.A. and Friedrich, M. (2009) Antitumor activity of an EpCAM/CD3-bispecific BiTE antibody during long-term treatment of mice in the absence of T-cell anergy and sustained cytokine release. Journal of Immunotherapy, 32, 452-464. doi:10.1097/CJI.0b013e3181a1c097

[10] Asano, R., Kawaguchi, H., Watanabe, Y., Nakanishi, T., Umetsu, M., Hayashi, H., Katayose, Y., Unno, M., Kudo, T. and Kumagai, I. (2008) Diabody-based recombinant formats of humanized IgG-like bispecific antibody with effective retargeting of lymphocytes to tumor cells. Journal of Immunotherapy, 31, 752-761.

doi:10.1097/CJI.0b013e3181849071

[11] Buhler, P., Molnar, E., Dopfer, E.P., Wolf, P., Gierschner, D., Wetterauer, U., Schamel, W.W. and Elsasser-Beile, U. (2009) Target-dependent T-cell activation by coligation with a PSMA x CD3 diabody induces lysis of prostate cancer cells. Journal of Therapy, 32, 565-573.

[12] Kellner, C., Bruenke, J., Stieglmaier, J., Schwemmlein, M., Schwenkert, M., Singer, H., Mentz, K., Peipp, M., Lang, P., Oduncu, F., Stockmeyer, B. and Fey, G.H. (2008) A novel CD19-directed recombinant bispecific antibody derivative with enhanced immune effector functions for human leukemic cells. Journal of Immunotherapy, 31, 871884. doi:10.1097/CJI.0b013e318186c8b4

[13] Lutterbuese, R., Raum, T., Kischel, R., Lutterbuese, P., Schlereth, B., Schaller, E., Mangold, S., Rau, D., Meier, P., Kiener, P.A., Mulgrew, K., Oberst, M.D., Hammond, S.A., Baeuerle, P.A. and Kufer, P. (2009) Potent control of tumor growth by CEA/CD3-bispecific single-chain antibody constructs that are not competitively inhibited by soluble CEA. Journal of Immunotherapy, 32, 341-352. doi:10.1097/CJI.0b013e31819b7c70

[14] Sebastian, M., Kiewe, P., Schuette, W., Brust, D., Peschel, C., Schneller, F., Ruhle, K.H., Nilius, G., Ewert, R., Lodziewski, S., Passlick, B., Sienel, W., Wiewrodt, R., Jager, M., Lindhofer, H., Friccius-Quecke, H. and Schmittel, A. (2009) Treatment of malignant pleural effusion with the trifunctional antibody catumaxomab (Removab) (antiEpCAM x Anti-CD3): results of a phase 1/2 study. Journal of Immunotherapy, 32, 195-202. doi:10.1097/CJI.0b013e318195b5bb

[15] Xiong, D., Xu, Y., Liu, H., Peng, H., Shao, X., Lai, Z.,
Fan, D., Yang, M., Han, J., Xie, Y., Yang, C. and Zhu, Z. (2002) Efficient inhibition of human B-cell lymphoma xenografts with an anti-CD20 x anti-CD3 bispecific diabody. Cancer Letters, 1, 77, 29-39. doi:10.1016/S0304-3835(01)00758-3

[16] Jensen, M., Ernestus, K., Kemshead, J., Klehr, M., Von Bergwelt-Baildon, M.S., Schinkothe, T., Schultze, J.L. and Berthold, F. (2003) The bi-specific CD3 x NCAM antibody: A model to preactivate T cells prior to tumour cell lysis. Clinical and Experimental Immunology, 134, 253-263. doi:10.1046/j.1365-2249.2003.02300.x

[17] Grosse-Hovest, L., Brandl, M., Dohlsten, M., Kalland, T., Wilmanns, W. and Jung, G. (1999) Tumor-growth inhibition with bispecific antibody fragments in a syngeneic mouse melanoma model: The role of targeted T-cell costimulation via CD28. International Journal of Cancer, 80, 138-144. doi:10.1002/(SICI)1097-0215(19990105)80:1<138::AIDIJC25>3.0.CO;2-J

[18] Jung, G., Brandl, M., Eisner, W., Fraunberger, P., Reifenberger, G., Schlegel, U., Wiestler, O. and Wilmanns, W. (2001) Local immunotherapy of glioma patients with a combination of 2 bispecific antibody fragments and resting autologous lymphocytes: Evidence for in situ Tcell activation and therapeutic efficacy. International Journal of Cancer, 91, 225-230.

doi:10.1002/1097-0215(200002)9999:9999<::AID-IJC10 38>3.3.CO;2-7

[19] Chames, P. and Baty, D. (2009) Bispecific antibodies for cancer therapy: The light at the end of the tunnel? Mabs, 1, 539-547. doi:10.4161/mabs.1.6.10015

[20] Verma, R., Boleti, E. and George, A.J. (1998) Antibody engineering: Comparison of bacterial, yeast, insect and mammalian expression systems. Journal of Immunological Methods, 216, 165-181.

doi:10.1016/S0022-1759(98)00077-5

[21] Jostock, T. and Knopf, H.P. (2012) Mammalian stable expression of biotherapeutics. Methods in Molecular Biology, 899, 227-238.

doi:10.1007/978-1-61779-921-1_15

[22] Young, C.L., Britton, Z.T. and Robinson, A.S. (2012) Recombinant protein expression and purification: A comprehensive review of affinity tags and microbial applications. Biotechnological Journal, 7, 620-634. doi:10.1002/biot.201100155

[23] Jensen, M. and Berthold, F. (2007) Targeting the neural cell adhesion molecule in cancer. Cancer Letters, 258, 921. doi:10.1016/j.canlet.2007.09.004

[24] Spannuth, W.A., Nick, A.M., Jennings, N.B., ArmaizPena, G.N., Mangala, L.S., Danes, C.G., Lin, Y.G., Merritt, W.M., Thaker, P.H., Kamat, A.A., Han, L.Y., Tonra, J.R., Coleman, R.L., Ellis, L.M. and Sood, A.K. (2009) Functional significance of VEGFR-2 on ovarian cancer cells. International Journal of Cancer, 124, 1045-1053. doi:10.1002/ijc. 24028

[25] Rapisarda, A. and Melillo, G. (2012) Role of the VEGF/ VEGFR axis in cancer biology and therapy. Advanced Cancer Research, 114, 237-267.

[26] Masood, R., Cai, J., Zheng, T., Smith, D.L., Hinton, D.R. 
and Gill, P.S. (2001) Vascular endothelial growth factor $8 \mathrm{VEGF}$ ) is an autocrine growth factor for VEGF receptor-positive human tumors. Blood, 98, 1904-1913. doi:10.1182/blood.V98.6.1904

[27] Böldicke, T., Tesar, M., Griesel, C., Rohde, M., Grone, H. J., Waltenberger, J., Kollet, O., Lapidot, T., Yayon, A. and Weich, H. (2001) Anti-VEGFR-2 scFvs for cell isolation. Single-chain antibodies recognizing the human vascular endothelial growth factor receptor-2 (VEGFR-2/ flk-1) on the surface of primary endothelial cells and preselected CD34+ cells from cord blood. Stem Cells, 19, 24-36. doi:10.1634/stemcells.19-1-24

[28] Frankel, A.E., Zuckero, S.L., Mankin, A.A., Grable, M., Mitchell, K., Lee, Y.J., Neville, D.M. and Woo, J.H. (2009) Anti-CD3 recombinant diphtheria immunotoxin therapy of cutaneous T cell lymphoma. Current Drug Targets, 10, 104-109. doi:10.2174/138945009787354539

[29] Grosse-Hovest, L., Hartlapp, I., Marwan, W., Brem, G., Rammensee, H. and Jung, G. (2003) A recombinant bispecific single-chain antibody induces targeted, supra-agonistic CD28-stimulation and tumor cell killing. European Journal of Immunology, 33, 1334-1340. doi:10.1002/eji.200323322

[30] Böldicke, T., Somplatzki, S., Sergeev, G. and Mueller, P. P. (2012) Functional inhibition of transitory proteins by intrabody-mediated retention in the endoplasmatic reticulum. Methods, 56, 338-350. doi:10.1016/j.ymeth.2011.10.008

[31] Minsky, A., Summers, R.G. and Knowles, J.R. (1986) Secretion of beta-lactamase into the periplasm of Escherichia coli: Evidence for a distinct release step associated with a conformational change. Proceedings of National Academy Science of the USA, 83, 4180-4184. doi:10.1073/pnas.83.12.4180

[32] Waltenberger, J., Claesson-Welsh, L., Siegbahn, A., Shibuya, M. and Heldin, C. H. (1994) Different signal transduction properties of KDR and Flt1, two receptors for vascular endothelial growth factor. Journal of Biological
Chemistry, 269, 26988-26995.

[33] Wigler, M., Sweet, R., Sim, G.K., Wold, B., Pellicer, A., Lacy, E., Maniatis, T., Silverstein, S. and Axel, R. (1979) Transformation of mammalian cells with genes from procaryotes and eucaryotes. Cell, 16, 777-785. doi:10.1016/0092-8674(79)90093-X

[34] Smith, P.K., Krohn, R.I., Hermanson, G.T., Mallia, A.K., Gartner, F.H., Provenzano, M.D., Fujimoto, E.K., Goeke, N.M., Olson, B.J. and Klenk, D.C. (1985) Measurement of protein using bicinchoninic acid. Analytical Biochemistry, 150, 76-85. doi:10.1016/0003-2697(85)90442-7

[35] Burnette, W.N. (1981) "Western blotting”: Electrophoretic transfer of proteins from sodium dodecyl sulfate-polyacrylamide gels to unmodified nitrocellulose and radiographic detection with antibody and radioiodinated protein A. Analytical Biochemistry, 112, 195-203. doi:10.1016/0003-2697(81)90281-5

[36] Kung, P., Goldstein, G., Reinherz, E.L. and Schlossman, S.F. (1979) Monoclonal antibodies defining distinctive human T cell surface antigens. Science, 206, 347-349. doi:10.1126/science.314668

[37] Bourne, S.P., Patel, K., Walsh, F., Popham, C.J., Coakham, H.B. and Kemshead, J.T. (1991) A monoclonal antibody (ERIC-1), raised against retinoblastoma, that recognizes the neural cell adhesion molecule (NCAM) expressed on brain and tumours arising from the neuroectoderm. Journal of Neurooncology, 10, 111-119. doi:10.1007/BF00146871

[38] Whittington, H.A., Hancock, J. and Kemshead, J.T. (2001) Generation of a humanised single chain Fv (Scfv) derived from the monoclonal Eric-1 recognising the human neural cell adhesion molecule. Medical and Pediatric Oncology, 36, 243-246. doi:10.1002/1096-911X(20010101)36:1<243::AID-MPO 1060>3.0.CO;2-5

[39] Pluckthun, A. (2012) Ribosome display: A perspective. Methods in Molecular Biology, 805, 3-28. doi:10.1007/978-1-61779-379-0 1 